\title{
REVISED VISIT-TS: A multimedia tool for population studies on tic
}

\section{disorders [version 2; peer review: 3 approved]}

Previously titled: VISIT-TS version 2: A multimedia tool for population studies on tic disorders

\author{
M. Jonathan Vachon', Catherine W. Striley2, Mollie R. Gordon³, \\ Miriam L. Schroeder ${ }^{4}$, Emily C. Bihun ${ }^{5}$, Jonathan M. Koller (iD) 5 , Kevin J. Black (iD6 \\ ${ }^{1}$ College of Arts and Sciences, Washington University in St. Louis, University City, USA \\ 2Department of Epidemiology, Colleges of Medicine and Public Health \& Health Professions, University of Florida, Gainesville, USA \\ ${ }^{3}$ Menninger Department of Psychiatry and Behavioral Sciences, Baylor College of Medicine, Houston, USA \\ ${ }^{4}$ Private Practice, St. Louis, USA \\ ${ }^{5}$ Department of Psychiatry, Washington University School of Medicine, St. Louis, USA \\ ${ }^{6}$ Departments of Psychiatry, Neurology, Radiology, and Neuroscience, Washington University School of Medicine, St. Louis, USA
}

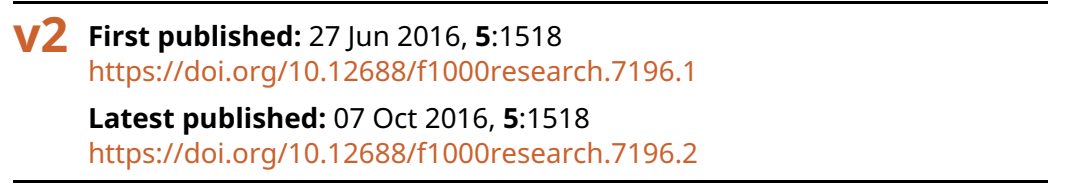

\section{Abstract}

Population-based assessment of Tourette syndrome (TS) and other tic disorders produces a paradox. On one hand, ideally diagnosis of tic disorders requires expert observation. In fact, diagnostic criteria for TS explicitly require expert assessment of tics for a definite diagnosis. On the other hand, large-scale population surveys with expert assessment of every subject are impracticable. True, several published studies have successfully used expert assessment to find tic prevalence in a representative population (e.g. all students in a school district). However, extending these studies to larger populations is daunting.

We created a multimedia tool to demonstrate tics to a lay audience, discuss their defining and common attributes, and address features that differentiate tics from other movements and vocalizations. A first version was modified to improve clarity and to include a more diverse group in terms of age and ethnicity. The result is a tool intended for epidemiological research. It may also provide additional benefits, such as more representative minority recruitment for other TS studies and increased community awareness of TS.

\section{Keywords}

Tourette syndrome, prevalence, epidemiology , method, video-audio media, video recording

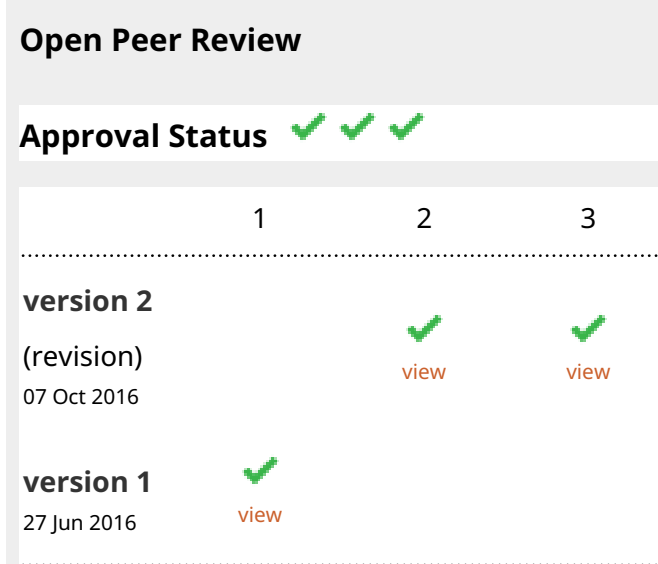

1. Kerstin J. Plessen, University of Copenhagen, Copenhagen, Denmark

Mental Health Services - Capital Region of Denmark, Copenhagen, Denmark

Julie Hagstrøm, Mental Health Services Capital Region of Denmark, Copenhagen, Denmark

2. David R. Shprecher, Banner Sun Health Research Institute, Sun City, USA University of Utah, Salt Lake City, USA

3. Shawn Smyth, Johns Hopkins School of Medicine, Baltimore, USA Sinai Hospital, Baltimore, USA 


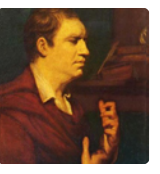

This article is included in the Tics collection.
James R. Brašić, Johns Hopkins University

School of Medicine, Baltimore, USA

Any reports and responses or comments on the article can be found at the end of the article.

Corresponding author: Kevin J. Black (kevin@wustl.edu)

Competing interests: VISIT-TS is published under a CC BY-NC-ND license, i.e. freely available for noncommercial uses. Funds from any future commercial application of VISIT-TS are intended to benefit research on or clinical care for tic disorders.

Grant information: Funded by research grants from the Tourette Syndrome Association to CWS and by the National Institutes of Health (K24 MH087913, to KJB).

The funders had no role in study design, data collection and analysis, decision to publish, or preparation of the manuscript.

Copyright: $\odot 2016$ Vachon MJ et al. This is an open access article distributed under the terms of the Creative Commons Attribution License, which permits unrestricted use, distribution, and reproduction in any medium, provided the original work is properly cited.

How to cite this article: Vachon MJ, Striley CW, Gordon MR et al. VISIT-TS: A multimedia tool for population studies on tic disorders [version 2; peer review: 3 approved] F1000Research 2016, 5:1518 https://doi.org/10.12688/f1000research.7196.2

First published: 27 Jun 2016, 5:1518 https://doi.org/10.12688/f1000research.7196.1 


\section{REVISED Amendments from Version 1}

This revised manuscript simplifies the title and includes minor changes in response to reviewers' suggestions.

Our primary intent was to help lay people decide whether they (or their child) had any tics, not to distinguish which tics they had. We had chosen to present and ask about different tics separately in order to increase sensitivity, but the comments by Drs. Plessen and Hagstrøm suggest that this choice may have unnecessarily lengthened the video, and was not clearly explained in the text. We now acknowledge this point in the last two sentences of Discussion. We also add the omitted original reference for the YGTSS.

Dr. Malaty commented on the probably limited specificity of VISIT TS, since respondents may mistake other normal or abnormal movements for tics. We agree with these comments and acknowledge this point in the last paragraph of Discussion.

See referee reports
\& von Knorring, 2003; Khalifa \& von Knorring, 2005; Kurlan et al., 1994; Lanzi et al., 2004; Mason et al., 1998; Wang \& Kuo, 2003) generally report a several-fold higher prevalence of tic disorders than do other epidemiological studies (CDC, 2009; Scahill et al., 2014).

To address these issues, we developed a multimedia screening interview to enhance population-based ascertainment of tic disorders by lay interviewers ("VISIT-TS", Gordon et al., 2010). A video presented and discussed typical tics, addressed a few difficulties in differential diagnosis, and then presented questions to gather the information required for diagnosis by DSM-IV-TR (American Psychiatric Association, 2000) and DSM-5 (American Psychiatric Association, 2013). After initial testing and application (unpublished report, Striley CW, Black KJ, Kelso N, and Vagelakos L), we revised the instrument. Here we describe the approach we took and the result: VISIT-TS v. 2.

\section{Methods}

We first reviewed previous methods including the Yale Child Study Center questionnaire (Findley et al., 1999; Jagger et al., 1982), the Kiddie SADS semi-structured interview (K-SADSPL) (Kaufman et al., 1997) and the interviews used by Apter et al. (1993); Gillberg \& Rasmussen (1982, Appendix); Hornsey et al. (2001) and Mason et al. (1998) who used the Apter questions and the National Hospital Interview Schedule for GTS (Rickards \& Robertson, 2003; Robertson \& Eapen, 1996); Appendix I in Khalifa \& von Knorring (2003); and Table 1 in Linazasoro et al. (2006). We also reviewed the Diagnostic Confidence Index (Robertson et al., 1999), the YGTSS (Leckman et al., 1989; Storch et al., 2005), and the parent and child self-report forms used by the Tourette Syndrome Association International Consortium for Genetics (1999). An expert in psychiatric epidemiology (CWS) developed the questions that would be posed, in consultation with a movement-disorders-trained neuropsychiatrist (KJB). The interview was designed to address both current (past month) and lifetime symptoms and included information needed for TSSG, DSM-IV-TR and DSM-5 criteria for TS.

We wrote a script addressing the following aims: demonstrate tics, discuss their defining and common attributes, and address features that differentiate tics from other movements and vocalizations. We then selected video clips from patients and research volunteers who gave written permission to re-use their video separately from patient care or the research study they had participated in. We also obtained permission from people with tics to re-use selected video clips that they had already made publicly available on YouTube. The final video was produced by Ty Travis (San Tan Valley, Arizona, USA). We dubbed the final product VISIT-TS, for "VideoIntegrated Screening Instrument for Tics and Tourette Syndrome" (Gordon et al., 2010).

The first version of VISIT-TS was used in an initial reliability and validity study that provided experience and initial feedback from interviewees and staff (unpublished report, Striley CW, Black KJ, Kelso N, and Vagelakos L). It was also shared with about a dozen other movement disorders experts and we reviewed their feedback. In response to this initial experience and feedback, we made many changes, including new video clips, thereby reducing the amount of time the narrator is shown and showing more diversity in ethnicity
We were especially concerned that some respondents with tics, or whose children had tics, might not correctly interpret written descriptions of tics but would recognize the tics if they saw them. Supporting the potential importance of this concern, epidemiological studies that included expert examination (Comings et al., 1990; Cubo et al., 2011; Hornsey et al., 2001; Jin et al., 2005; Khalifa 
and age. We added and improved graphics, including written text while examples of tics appear in the background. To avoid confusion, we removed videos showing examples of non-tic movements, and we eliminated medical terms unfamiliar to the general public, such as chorea. Finally, we restored an unintentionally omitted question on lower facial tics. Here we describe the revised product, version 2 of VISIT-TS.

\section{Results}

The revised VISIT-TS multimedia tool includes almost 100 video clips defining and demonstrating tics including simple and complex motor tics as well as simple and complex vocal tics, edited to a length of 5 minutes. Following the clips, 16 questions are presented in written and spoken form, one at a time, accompanied in most cases by brief video of the phenomenon being ascertained (see Appendix 1; question 4 of the video, at about 6:09, is a good brief demonstration). The questions take another 5 minutes. The video clips demonstrate adults and children in similar numbers, both sexes (male:female $\approx 5: 4$ ), and include some ethnic diversity (about 1 in 8 clips are Hispanic or non-white). VISITTS v. 2 is freely available for noncommercial use at https:// zenodo.org/collection/user-kjb or at http://dx.doi.org/10.5281/ zenodo.55604.

\section{Discussion}

This approach is based on the premise that survey respondents will respond more accurately about tics in themselves (or their children) after the interviewer shows them a brief video about tics than they would if only asked about history by questionnaire or by cross-sectional lay observation. Because tics can come and go, can be suppressed, and often resemble intentional movement or vocalizations, diagnosis of tic disorders can be challenging (Black et al., 2016; Cubo, 2012).

Some data are available to judge the sensitivity of lay diagnostic instruments for tic disorders. In two studies, about half of the children who had previously been diagnosed with TS were missed by research screening: 1 of 2 in Landgren et al., 1996 and 8 of 15 in Snider et al., 2002. Conversely, routine clinical assessment for tics is also insensitive; Kadesjo \& Gillberg (2000) report that a tic diagnosis had been considered during child psychiatric treatment in only 1 of 18 children with TS. Khalifa \& von Knorring (2003) examined the sensitivity of their questionnaire but only by comparing questionnaire responses from parents to those from teachers. It appears Wang \& Kuo (2003) collected physician examination data on questionnaire-negative children, but those data were not reported. Linazasoro et al. (2006) do not specify whether any of the tics diagnosed by a physician observing a classroom of students for 20 minutes were missed by parent or teacher questionnaires. Stefanoff et al. (2008) diagnosed a tic disorder in $6 \%$ of children whose parents and teachers noticed no tics; this is more remarkable given that the diagnosis rate in screen-positive children was only $18 \%$. Cubo et al. (2011) found sensitivities of $36 \%-73 \%$ for questionnaires completed by teachers, observers or parents. In a recent study, a semistandardized diagnostic interview (the DISC) captured only about half the cases of TS, and there was little agreement between DISC results and expert clinician diagnosis (Lewin et al., 2014).
The most detailed data on the sensitivity of questionnaires for tic diagnosis come from the study of Mason et al. (1998). They gave questionnaires containing the 4 tic screening questions of Apter et al. (1993) to students, parents and teachers. They also screened for tics with direct classroom observation by Dr. Mason, a psychologist trained in tic detection at the Queen Square, London, TS center; she watched each classroom for an hour, 2 minutes per student. To confirm the diagnosis, Mason then directly examined all 16 consenting screen-positive students in a traditional clinical setting. Importantly, Mason also examined 8 students randomly chosen from screen negatives, i.e. those who had no tics reported by themselves, parents, or teachers, and no tics observed in the classroom. Remarkably, 3 of the 8 had at least one tic when examined directly, counted only if it had been present for at least a year by history! This very high rate of missed chronic tic disorders (37.5\%) suggests that traditional questionnaires and interviews are insufficiently sensitive. VISIT-TS was designed to improve sensitivity by making sure subjects and parents have seen typical tics on video before answering questions about them.

Linazasoro \& colleagues (2006) used a method somewhat similar to the VISIT-TS approach, i.e., they showed a videotape of tics as part of an initial lecture to parents and teachers, followed by a survey that included a short written description of tics. Independently, "all children were directly observed in the classroom by an expert clinician in the field of tics who diagnosed tics based exclusively on the characteristics of the movements", with a limit of 20 minutes' observation per classroom (p. 2107). However, the authors note limitations of their work including the fact that children were observed collectively, for a relatively brief period of time, and while engaged in school work, when tics may have been suppressed. The questionnaires actually identified more children (98) than the expert (57), suggesting either that parents and teachers overdiagnosed some movements as tics, or that they were describing tics present in the past but no longer present, or that the classroom observation was not an adequately sensitive clinical comparison. A videotape demonstrating tics was released (Tourette Syndrome Association, 1990), but it was intended for a professional audience rather than for epidemiological studies.

The VISIT-TS also has limitations. The DSM and TSSG criteria explicitly require application by properly trained experts, so VISIT-TS is primarily intended as a screening tool rather than as a substitute for clinical expertise. The sensitivity of VISIT-TS has not been reported. Furthermore, its specificity may be limited; the video includes only minimal information that could help distinguish tics from chorea, dystonia, stereotypies (sensu stricto) or other abnormal movements, and after all such differential diagnosis generally requires clinical expertise. Nevertheless, a 5- to 10-minute video-illustrated questionnaire is probably a reasonable compromise for epidemiological or other tic studies that require screening large population samples for tic disorders. Finally, the video inquires separately about tics in different body locations, in hopes of improving sensitivity. However, since our primary intent was to identify presence or absence of tics, not to distinguish tics by body part affected, further experience with VISIT TS may allow shortening the video further by reducing the number of questions. 


\section{Data availability}

The video can be found here: http://dx.doi.org/10.5281/zenodo.55604 (Vachon et al., 2016).

Author contributions

MJV assembled video clips and wrote the first draft and KJB edited it. CWS and KJB drafted the questions. MJV, MRG and ECB identified video clips. CWS, MRG, JMK and KJB created the first version of the video. MJV, CWS, MRG, MLS and KJB contributed to the spoken script for the video. MJV and JMK edited video clips. All authors approved the final draft.

Competing interests

VISIT-TS is published under a CC BY-NC-ND license, i.e. freely available for noncommercial uses. Funds from any future commercial application of VISIT-TS are intended to benefit research on or clinical care for tic disorders.

\section{Grant information}

Funded by research grants from the Tourette Syndrome Association to CWS and by the National Institutes of Health (K24 MH087913, to $\mathrm{KJB}$ ).

The funders had no role in study design, data collection and analysis, decision to publish, or preparation of the manuscript.

\section{Acknowledgments}

The authors gratefully acknowledge all those who allowed their or their children's video clips to be included in VISIT-TS. Thanks to Ben Holt, Johanna Hartlein, Alison Stempel and Daniel Murray for work on this or the previous version, and to Ty Travis for video production.

\section{Supplementary material}

\section{Appendix 1}

Questions asked at the end of the VISIT-TS v. 2

1. Have you ever had eye movement tics?

2. Have you ever had repeated blinking or winking, like the tics in the video?

3. Have you ever had eyebrow tics?

4. Have you ever had mouth, tongue or jaw tics?

5. Does any part of your upper body, such as your head, shoulders, or arms jerk, turn or move unexpectedly or differently like in the video?

6. Has the middle or lower part of your body ever moved differently, like your stomach muscles contracting, your legs kicking or feet moving, over and over?

7. Have you sometimes repeated sounds over and over, like clicking, clucking, humming, grunting or smacking?

8. Have you sniffed or cleared your throat over and over, even when you didn't have allergies or a cold and your nose wasn't runny or itchy?

9. Have you had any repeated movements that are always done in the same way and involve more than one muscle group-like eyes and mouth, or shoulder plus arm? These tics may seem like they are being done on purpose or intentionally at times, but usually they are not.

10. Have you done things over and over like:
a. Adjusting your clothes?
b. Making obscene gestures?
c. Patting yourself?
d. Twisting your hair?
e. Scratching your foot inside your shoe?

11. Have you sometimes repeated words over and over, or yelled out phrases over and over?

12. The video showed several behaviors, including making noises and movements, that people did over and over. Do you feel you have any tic-like behavior that has not already been mentioned? If yes, please describe it.

if Yes to any previous question, continue:

13. Did your "YES" answer, or answers, refer to something that started before your 18th birthday, that is when you were age 0 through 17 years old? 
14. Did your "YES" answer, or answers, refer to something that happened many times a day most days for some period of time?

15. Did your "YES" answer, or answers, refer to something that kept happening over a period of a year or more?

if Yes to question 15, continue:

16. You said you had a year go by during which you had tics most of the time. During that year, did you ever have a time when all the tics were gone for 3 months straight?

American Psychiatric Association: Diagnostic and statistical manual of mental disorders. (4th ed., Text Revision). Washington, DC: American Psychiatric Association. 2000.

Reference Source

American Psychiatric Association: Diagnostic and statistical manual of mental disorders. (5th ed.). Arlington, VA: American Psychiatric Association. 2013. Publisher Full Text

Apter A, Pauls DL, Bleich A, et al.: An epidemiologic study of Gilles de la Tourette's syndrome in Israel. Arch Gen Psychiatry. 1993; 50(9): 734-8. PubMed Abstract | Publisher Full Text

Black KJ, Black ER, Greene DJ, et al.: Provisional Tic Disorder: What to tell parents when their child first starts ticcing [version 1; referees: 3 approved] F1000Res. 2016; 5: 696 .

PubMed Abstract | Publisher Full Text | Free Full Text

Centers for Disease Control and Prevention (CDC): Prevalence of diagnosed Tourette Syndrome in persons aged 6-17 Years - United States, 2007. MMWR Morb Mortal Wkly Rep. 2009; 58(21): 581-585.

PubMed Abstract

Comings DE, Himes JA, Comings BG: An epidemiologic study of Tourette's syndrome in a single school district. J Clin Psychiatry. 1990; 51(11): 463-9. PubMed Abstract

Costello EJ, Angold A, Burns BJ, et al:: The Great Smoky Mountains Study of Youth. Goals, design, methods, and the prevalence of DSM-III-R disorders. Arch Gen Psychiatry. 1996; 53(12): 1129-36.

PubMed Abstract | Publisher Full Text

Cubo E: Review of prevalence studies of tic disorders: methodological caveats. Tremor Other Hyperkinet Mov (N Y) . 2012; 2: pii: tre-02-61-349-1. PubMed Abstract | Publisher Full Text | Free Full Text

Cubo E, Sáez Velasco S, Delgado Benito V, et al.: Validation of screening instruments for neuroepidemiological surveys of tic disorders. Mov Disord. 2011; 26(3): 520-526.

PubMed Abstract | Publisher Full Text

Findley DB, King RA, Leckman JF: Yale Child Study Center Tourette's syndromeobsessive-compulsive disorder specialty clinic symptom questionnaire.

Appendix 1. In Leckman JF, Cohen DJ: Tourette's Syndrome-Tics, Obsessions, and Compulsions: Developmental Psychopathology and Clinical Care. New York: Wiley, 1999; 415-454.

Gillberg C, Rasmussen P: Perceptual, motor and attentional deficits in sevenyear-old children: background factors. Dev Med Child Neurol. 1982; 24(6): $752-70$

PubMed Abstract | Publisher Full Text

Gordon M, Striley C, Koller JM, et al:: VISIT-TS: Video-Integrated Screening Instrument for Tics and Tourette Syndrome. Annual meeting, American Neuropsychiatric Association, Tampa, FL, 17-20, March 2010. J Neuropsychiatry Clin Neurosci. 22(2): 246

Publisher Full Text

Hornsey $\mathrm{H}$, Banerjee $\mathrm{S}$, Zeitlin $\mathrm{H}$, et al:: The prevalence of Tourette syndrome in 13-14-year-olds in mainstream schools. J Child Psychol Psychiatry. 2001; 42(8): $1035-9$

PubMed Abstract | Publisher Full Text

Jagger J, Prusoff BA, Cohen DJ, et al.: The epidemiology of Tourette's

syndrome: a pilot study. Schizophr Bull. 1982; 8(2): 267-278.

PubMed Abstract| Publisher Full Text

Jin R, Zheng RY, Huang WW, et al:: Epidemiological survey of Tourette syndrome in children and adolescents in Wenzhou of P.R. China. Eur $J$ Epidemiol. 2005; 20(11): 925-7.

PubMed Abstract | Publisher Full Text

Kadesjö B, Gillberg C: Tourette's disorder: epidemiology and comorbidity in primary school children. J Am Acad Child Adolesc Psychiatry. 2000; 39(5): 548-55. PubMed Abstract | Publisher Full Text

Kaufman J, Birmaher B, Brent D, et al.: Schedule for Affective Disorders and Schizophrenia for School-Age Children-Present and Lifetime Version (K-SADSPL): initial reliability and validity data. J Am Acad Child Adolesc Psychiatry. 1997; 36(7): 980-8

PubMed Abstract | Publisher Full Text

Khalifa N, von Knorring AL: Prevalence of tic disorders and Tourette syndrome in a Swedish school population. Dev Med Child Neurol. 2003; 45(5): 315-9. PubMed Abstract | Publisher Full Text

Khalifa N, von Knorring AL: Tourette syndrome and other tic disorders in a total population of children: clinical assessment and background. Acta Paediatr. 2005; 94(11): 1608-14.

PubMed Abstract | Publisher Full Text

Kurlan R, Whitmore D, Irvine C, et al:: Tourette's syndrome in a specia education population: a pilot study involving a single school district. Neurology. 1994; 44(4): 699-702.

PubMed Abstract | Publisher Full Text

Lanzi G, Zambrino CA, Termine C, et al:: Prevalence of tic disorders among primary school students in the city of Pavia, Italy. Arch Dis Child. 2004; 89(1): $45-7$.

PubMed Abstract | Free Full Text

Landgren M, Pettersson R, Kjellman B, et al.: ADHD, DAMP and other neurodevelopmental/psychiatric disorders in 6-year-old children: epidemiology and co-morbidity. Dev Med Child Neurol. 1996; 38(10): 891-906. PubMed Abstract | Publisher Full Text

Lapouse R, Monk MA: Behavior deviations in a representative sample of children: variation by sex, age, race, social class and family size. $A m \mathrm{~J}$ Orthopsychiatry. 1964; 34: 436-46.

PubMed Abstract | Publisher Full Text

Leckman JF, Riddle MA, Hardin MT, et al:: The Yale Global Tic Severity Scale: initial testing of a clinician-rated scale of tic severity. J Am Acad Child Adolesc Psychiatry. 1989; 28(4): 566-573.

PubMed Abstract | Publisher Full Tex

Lewin $\mathrm{AB}$, Mink JW, Bitsko $\mathrm{RH}$, et al: Utility of the diagnostic interview schedule for children for assessing Tourette syndrome in children. $J$ Child Adolesc Psychopharmacol. 2014; 24(5): 275-84.

PubMed Abstract | Publisher Full Text | Free Full Tex

Linazasoro G, Van Blercom N, de Zárate CO: Prevalence of tic disorder in two schools in the Basque country: Results and methodological caveats. Mov Disord. 2006; 21(12): 2106-2109.

PubMed Abstract | Publisher Full Tex

Mason A, Banerjee S, Eapen V, et al:: The prevalence of Tourette syndrome in a mainstream school population. Dev Med Child Neurol. 1998; 40(5): 292-6. PubMed Abstract | Publisher Full Text

Olfson M, Crystal S, Gerhard T, et al:: Patterns and correlates of tic disorder diagnoses in privately and publicly insured youth. $J \mathrm{Am}$ Acad Child Adolesc Psychiatry. 2011; 50(2): 119-131.

PubMed Abstract | Publisher Full Tex

Peterson BS, Pine DS, Cohen P, et al:: Prospective, longitudinal study of tic, obsessive-compulsive, and attention-deficit/hyperactivity disorders in an epidemiological sample. J Am Acad Child Adolesc Psychiatry. 2001; 40: 685-695.

PubMed Abstract | Publisher Full Text

Rickards $\mathrm{H}$, Robertson M: A controlled study of psychopathology and associated symptoms in Tourette syndrome. World J Biol Psychiatry. 2003; 4(2): $64-8$.

PubMed Abstract | Publisher Full Text 
Robertson MM, Banerjee S, Kurlan R, et al.: The Tourette syndrome diagnostic confidence index: development and clinical associations. Neurology. 1999; 53(9): 2108-12.

PubMed Abstract | Publisher Full Text

Robertson MM, Eapen V: The National Hospital Interview Schedule for the assessment of Gilles de la Tourette syndrome. Int J Methods Psychiatr Res. 1996; 6(4): 203-226.

Reference Source

Robertson MM, Eapen V, Cavanna AE: The international prevalence,

epidemiology, and clinical phenomenology of Tourette syndrome: a crosscultural perspective. J Psychosom Res. 2009; 67(6): 475-83.

PubMed Abstract | Publisher Full Text

Scahill L, Specht M, Page C: The Prevalence of Tic Disorders and Clinical

Characteristics in Children. J Obsessive Compuls Relat Disord. 2014; 3(4): 394-400. PubMed Abstract | Publisher Full Text | Free Full Text

Snider LA, Seligman LD, Ketchen BR, et al.: Tics and problem behaviors in schoolchildren: prevalence, characterization, and associations. Pediatrics. 2002; 110(2 Pt 1): 331-6.

PubMed Abstract
Stefanoff P, Wolanczyk T, Gawrys A, et al.: Prevalence of tic disorders among schoolchildren in Warsaw, Poland. Eur Child Adolesc Psychiatry. 2008; 17(3): 171-8. PubMed Abstract | Publisher Full Text

Storch EA, Murphy TK, Geffken GR, et al.: Reliability and validity of the Yale Global Tic Severity Scale. Psychol Assess. 2005; 17(4): 486-91.

PubMed Abstract | Publisher Full Text

The Tourette Syndrome Association International Consortium for Genetics: A complete genome screen in sib pairs affected by Gilles de la Tourette syndrome. Am J Hum Genet. 1999; 65(5): 1428-36.

PubMed Abstract | Publisher Full Text | Free Full Text

Tourette Syndrome Association: Tourette Syndrome: A Guide to Diagnosis. VHS videotape, 28 minutes. Tourette Syndrome Association, Bayside, NY, (C) 1990.

Vachon MJ, Striley CW, Gordon MR, et al:: VISIT-TS version 2 video (release 20160516). Zenodo. 2016.

Publisher Full Text

Wang HS, Kuo MF: Tourette's syndrome in Taiwan: an epidemiological study of tic disorders in an elementary school at Taipei County. Brain Dev. 2003; 25(Suppl 1): S29-31

PubMed Abstract | Publisher Full Tex 


\title{
Open Peer Review
}

\section{Current Peer Review Status:}

\section{Version 2}

Reviewer Report 07 November 2016

https://doi.org/10.5256/f1000research.10427.r16869

(C) 2016 Smyth S et al. This is an open access peer review report distributed under the terms of the Creative Commons Attribution License, which permits unrestricted use, distribution, and reproduction in any medium, provided the original work is properly cited.

\author{
Shawn Smyth \\ 1 Johns Hopkins School of Medicine, Baltimore, MD, USA \\ 2 Sinai Hospital, Baltimore, MD, USA
}

\section{James R. Brašić}

The Russell H. Morgan Department of Radiology and Radiological Science, Johns Hopkins University School of Medicine, Baltimore, MD, USA

Vachon and colleagues present a structured assessment designed to assist trained lay interviewers in assessing Tourette syndrome and other tic disorders in larger population studies. This tool is a well thought out instrument that will likely help fill a void in the area of the epidemiology of tic disorders. The use of trained lay interviewers to conduct structured psychiatric interviews has been used for population studies of children, adolescents, and adults with possible mental disorders. However, merely viewing a video may not be adequate to train people to distinguish movement disorders. Interrater reliability can verify the skills of a trained rater to identify the movements. However, the publication of this article can be justified by the dearth of trained individuals to screen large populations. This article may provide a tool to advance population studies around the world. We think only minor revisions might be needed.

The title is confusing as it employs an acronym which should either be defined within the title, or the title could be changed to not include the name of the instrument. Readers may be unfamiliar with the tool. Since the instrument has a long name, the title of the article could simply describe the procedure, e.g., "A strategy for conducting population studies of Tourette syndrome utilizing trained lay raters."

The abstract represents a suitable summary of the work and is adequate in its description of the study tool and design. Unlike articles presenting instruments along with psychometric properties (Goetz et al., 2008), this article presents a tool without any properties, results of use, or other such data. Thus, the abstract can be enhanced by describing the limitations of this tool (i.e. lack of reliability and validity data) while still making it clear that the instrument is being offered to the research and lay communities given the lack of adequate tools for population studies on tic disorders. 
Regarding the article content, please define the acronyms. In particular, under Methods in the last line of the first paragraph, "TSSG" may be unfamiliar to readers. However, the design and methods are adequately explained and are appropriate for a publication which addresses the struggles of doing epidemiological studies on tic disorders.

It is less typical for a study to review the development of a tool without some preliminary data when applying the tool to the population. As F1000Research features quick and transparent publications which can then be openly reviewed and digested by the scientific community, we think it would be an optimal environment to include the unpublished preliminary reliability and validity data of the VISIT-TS (first version). This would be adequate to assist the readers of this journal to make some assessment of the suitability of this procedure for scientific research. Alternatively, the information about the unpublished reliability and validity studies conducted by the authors can be presented as a separate pilot study.

The discussion could be improved by focusing a little more on the actual VISIT-TS and what is known about it, and less on the limitations of our current research methods and tools. Some of the latter information would be better incorporated into the introduction, which already reviews the current state of epidemiological research in tic disorders and makes a case for why the VISITTS is needed. Readers would also be very interested in the authors' ideas regarding possible future research directions or studies that could be performed with this multimedia tool, such as:

A group of lay individuals could be trained to use this strategy. Then the trained raters could be presented a series of new videotapes of people with and without tics. The findings could be compared and contrasted with the findings of expert raters.

Populations from the community could be given tests about tics before and after viewing the video to assess whether the video is an effective tool to educate children, parents, teachers, and members of the general community how to identify tics.

Evaluation of the reliability and validity of this procedure could be performed in multiple future studies with different populations.

Both the included video and list of questions are very helpful for the readers' understanding regarding how this tool is administered and what the experience is like for the participants.

\section{References}

1. Goetz CG, Tilley BC, Shaftman SR, Stebbins GT, et al.: Movement Disorder Society-sponsored revision of the Unified Parkinson's Disease Rating Scale (MDS-UPDRS): scale presentation and clinimetric testing results.Mov Disord. 2008; 23 (15): 2129-70 PubMed Abstract | Publisher Full Text

Competing Interests: No competing interests were disclosed.

We confirm that we have read this submission and believe that we have an appropriate level of expertise to confirm that it is of an acceptable scientific standard.

Reviewer Report 31 October 2016

https://doi.org/10.5256/f1000research.10427.r16867 
(c) 2016 Shprecher D. This is an open access peer review report distributed under the terms of the Creative Commons Attribution License, which permits unrestricted use, distribution, and reproduction in any medium, provided the original work is properly cited.

\section{David R. Shprecher}

1 Banner Sun Health Research Institute, Sun City, AZ, USA

2 Department of Neurology, University of Utah, Salt Lake City, UT, USA

The authors carefully reviewed the epidemiology of tics and Tourette syndrome and explained the need for more sensitive, broadly applicable screening tools. To address this need, they have developed a 10-minute video that shows nearly 100 tic examples and then asks a brief screening questionnaire.

The introductory section could benefit from some reference to the Avon study, which is considered landmark, as it was the only prospective, population-based study on prevalence of chronic tic disorders in a birth cohort (Scharf JM et al,. 2012).

The video has already been improved with input from the first round of reviewers. In order to avoid overwhelming or confusing the layperson, non-tic hyperkinetic disorders are appropriately left out. The emphasis was appropriately on improving sensitivity, so that potential tic disorders can be identified and further screened by a researcher or clinician. However, there still was one instance where the video appears to have sacrificed sensitivity and waded into murky waters. This is where examples of repetitive behaviors that are not tics (because they are compulsions) were given. Repetitive hand washing was a great example. However repeating a movement a certain number of times "because it feels right" may not be an appropriate example. Compulsions are performed to relieve anxiety, however compulsive tics are performed in order to relieve an urge (which can include evening out or repetition.) There is still equipoise about how to classify compulsive tics, therefore; in order to maintain sensitivity of the instrument, this clip might best be modified to use a more classic example of a compulsion (i.e., checking that the lights are off or the door is locked, even though you've just checked.)

There are a couple of concerns about the diagnostic utility of the questionnaire at the end of the video. Question \#10 on the screening interview at the end of the video ("Have you ever done things over and over like:)") gave 2 apt examples ("obscene gestures" and "patting yourself") but there rest are habits that are probably not specific enough for tic disorders. These include "twisting your hair," "scratching your foot inside your shoe" or "adjusting your clothes." Unless there is data to support these behaviors as being specific to tic disorders, the examples in this question might be appropriately replaced with behaviors that are more specific to tic disorders. Examples might include, "repeating words or phrases," "flicking your fingers" and "poking or hitting yourself."

Another concern is that the questionnaire appears to be designed according to DSM-IV criteria, likely because the project was started before the DSM-V criteria for TS were finalized in 2013 (American Psychiatric Association, 2013 http://dsm.psychiatryonline.org/doi/10.1176/appi.books.9780890425596.dsm01). DSM-V removed the requirement that one year of tics be present consecutively during childhood (a total of one year must be present, but it does not need to be continuous, i.e. it can be separated over time). 
DSM-V also removed a 3-month tic free period as exclusion for the diagnosis of TS. This video appears to specifically ask about the 3-month tic free period. If it is going to be used to screen according to current DSM-V criteria, then this question should be removed.

The discussion aptly points out how poorly specific a brief interview with children can be for diagnosis of tics (with $37.5 \%$ being missed even after 2 hours of observation by an expert.) The discussion could be improved in two ways. First, it could point out an additional potential value of this video beyond screening the public for tics. Along these lines, it could be useful in training researchers and even their staff to conduct broad scale assessments of tics. For example, the Monroe County study at the University of Rochester (Kurlan R et al,. 2001), trained technicians using 25 different video examples of tics before they went on to conduct a total of 1596 interviews of school children. They found a much higher prevalence of chronic tics, TS, and tics NOS than other epidemiological studies using less sensitive methods have (18.5 \% of children had at least some form of tic, and 7\% were found to have TS). This is much higher than other epidemiological research, but used a more sensitive (yet less specific instrument). A second improvement to the discussion would be, following the limitations section, a conclusion that proposes next steps. For example, a validation study could be proposed. Additionally, further improvements to the instrument could be considered (in the future) to create educational tools aimed at improving diagnostic sensitivity of clinicians (and researchers) and raising awareness about tics in the general population (particularly minorities that are hard to reach, and may be under-diagnosed.)

\section{References}

1. Scharf JM, Miller LL, Mathews CA, Ben-Shlomo Y: Prevalence of Tourette syndrome and chronic tics in the population-based Avon longitudinal study of parents and children cohort.J Am Acad Child Adolesc Psychiatry. 2012; 51 (2): 192-201.e5 PubMed Abstract | Publisher Full Text

2. American Psychiatric Association: Neurodevelopmental Disorders. 2013. Publisher Full Text 3. Kurlan R, McDermott MP, Deeley C, Como PG, et al.: Prevalence of tics in schoolchildren and association with placement in special education.Neurology. 2001; 57 (8): 1383-8 PubMed Abstract

Competing Interests: In the past 12 months; I have received speaking and/or consulting fees from Teva, Lundbeck, and the Tourette Association of America (TAA). I have received Center of Excellence program funding from the TAA and research support from the Arizona Alzheimer's Consortium, Adamas, Axovant, Intec, Neurocrine, Teva, US World Meds, Kyowa, Michael J Fox Foundation, and the NIH. The TAA provides education to a broad audience, and advocacy for individuals impacted by Tourette syndrome. Neurocrine and Teva are developing tic-suppressing treatments for Tourette syndrome.

\section{I confirm that I have read this submission and believe that I have an appropriate level of expertise to confirm that it is of an acceptable scientific standard.}

Author Response ( F1000Research Advisory Board Member) 31 Oct 2016

Kevin J Black, Washington University School of Medicine, St. Louis, USA

I am very appreciative of Dr. Shprecher's thoughtful comments.

We envisioned VISIT-TS being used primarily for screening, a setting in which sensitivity was more of a concern than specificity, so we were trying to be inclusive. 
Still, in retrospect, I think overall I agree with the suggestions on compulsions and other repetitive behaviors.

The comment about DSM-IV-TR is correct, but we chose to leave in the 3 questions about timing ("many times a day most days," "kept happening over a period of a year or more," and no 3-month period without tics). We argue that the 3-month question can simply be ignored for DSM-5, and my colleagues and I (at least) are still interested in DSM-IV-TR diagnoses. Nevertheless, to best fit DSM-5, which removed the "many times a day ... nearly every day" requirement, we probably should add a question like, "Was your first tic at least one year before your most recent tic?"

Similarly, we may consider changing the age of onset question to ask for a(n approximate) age rather than a dichotomous yes or no regarding before age 18 . My read of the science is that the age limit should probably be around age $21-25$, and the TSSG criteria required age 21 rather than 18 [1].

The comments on the introduction and discussion are also helpful.

Again, thanks.

[1] The Tourette Syndrome Classification Study Group. Definitions and classification of tic disorders. Arch Neurol. 1993 Oct. 50(10):1013-6. [Medline].

Competing Interests: No competing interests were disclosed.

\section{Version 1}

Reviewer Report 12 July 2016

\section{https://doi.org/10.5256/f1000research.7752.r14613}

(C) 2016 Plessen K et al. This is an open access peer review report distributed under the terms of the Creative Commons Attribution License, which permits unrestricted use, distribution, and reproduction in any medium, provided the original work is properly cited.

\section{Kerstin J. Plessen}

${ }^{1}$ Department of Clinical Medicine, Faculty of Health and Medical Sciences, University of Copenhagen, Copenhagen, Denmark

${ }^{2}$ Child and Adolescent Mental Health Centre, Mental Health Services - Capital Region of Denmark, Copenhagen, Denmark

Julie Hagstrøm

Child and Adolescent Mental Health Centre, Mental Health Services - Capital Region of Denmark, Copenhagen, Denmark 
In the article "VISIT-TS version 2: A multimedia tool for population studies on tic disorders" by Vachon, MJ, Striley, CW, Gordon, MR, Schroeder, ML., Bihun, EC, Koller, JM, and Black, KJ, a new method of classifying tics by lay persons is proposed as an aid in larger scale population studies.

The authors provide a clear account for the need for improving existing methods of detecting and differentiating tics and present an interesting solution in the form of their new multimedia tool. It is a positive aspect that participants with tics include different age groups, races, and both sexes. However, some of the video clips present one separate tic, whereas several tics are present in the video.

The rationale for developing the screening tool is its integration in large-scale epidemiological studies. Even though a few epidemiological studies focusing on tics and Tourette have been carried through, future methods will probably offer possibilities for screening cohorts for several co-occurring conditions. The authors may thus consider the possibility of further pruning the video (almost 10 minutes) and comparing two versions (e.g. the long one and a shorter version focusing on the different types of tics, which are more or less presented in the first few minutes of the video) for their validity against expert ratings. The shorter the time used for a screening, the more it will be used in big cohort studies. This could be integrated into future perspectives at the end of the manuscript.

It would also be interesting to carry out similar tests of the sensitivity as mentioned in the article by comparing the VISTS-TS to clinician ratings.

Storch et al. (2005) is used as a reference for the YGTSS - the authors might consider adding the reference of Leckman's (1989) original work.

Competing Interests: No competing interests were disclosed.

We confirm that we have read this submission and believe that we have an appropriate level of expertise to confirm that it is of an acceptable scientific standard.

Author Response ( F1000Research Advisory Board Member) 12 Jul 2016

Kevin J Black, Washington University School of Medicine, St. Louis, USA

We appreciate the thoughtful suggestions from Drs. Plessen and Hagstrøm.

Our primary intent was to help lay people decide whether they (or their child) had any tics, not to distinguish which tics they had. I see from your response that we did not make that point clear. I think there are benefits to presenting and asking about different tics separately, even for our more limited goal, but your perspective also suggests an opportunity to shorten or otherwise improve on the video.

You wrote, "some of the video clips present one separate tic, whereas several tics are present in the video." I believe you are saying that some video clips may show two tics while the narration is discussing only one of them. If I understood that correctly, it's a good point that we had not considered. We may be able to address that in a future version of the video. 
Competing Interests: No competing interests were disclosed.

\section{Comments on this article}

\section{Version 2}

Author Response ( F1000Research Advisory Board Member ) 31 Mar 2022

Kevin J Black, Washington University School of Medicine, St. Louis, USA

A survey of parents in three countries showed that reactions to tics differed among the countries, whereas severity of tics was similar (Stiede et al, 2021). This finding supports an additional possible hypothesis to explain the differences in tic prevalence among Americans of different racial or ethnic backgrounds; namely, that some groups may be more accepting of differences in behavior or have concerns (such as consequences of racism) that push attention to tics onto the back burner.

Stiede JT, Woods DW, Anderson S, Eapen V, Gev E, Latimer R, Bredesen AM: Cultural differences in reactions to tics and tic severity. Child \& Family Behavior Therapy 43(3):161-180, 2021. DOI 10.1080/07317107.2021.1940586

Competing Interests: No competing interests were disclosed.

Author Response ( F1000Research Advisory Board Member ) 24 Oct 2020

Kevin J Black, Washington University School of Medicine, St. Louis, USA

On re-reading the epidemological study by Gadow et al, 1 "A significantly higher percentage of African-American than white children received tic ratings in preschool (35\% versus $17 \%$ ) and elementary school (11\% versus $3 \%)$, but not secondary school (11\% versus $7 \%)$." They speculated that this result might be explained by the higher rate of ADHD in African-American children and the higher rate of tics in ADHD. ${ }^{2}$ This adds another study to those noted above showing higher rates of tic disorders in Black children in the U.S.

1. Gadow KD, Nolan EE, Sprafkin J, Schwartz J: Tics and psychiatric comorbidity in children and adolescents. Dev Med Child Neurol 2002; 44:330-338.

2. Black KJ: Tics in ADHD. 27 Feb 2019. https://tics.wustl.edu/tics-in-adhd/ Accessed 24 Oct 2020.

Competing Interests: No competing interests were disclosed. 
Kevin J Black, Washington University School of Medicine, St. Louis, USA

Appendix 1 above omits explanatory text we added to 2 questions, intended to reduce false positives. Here is the missing text:

- 3. Have you ever had eyebrow tics? Don't count little twitches of your eyelids that only happen for a few hours, once in a great while, and are probably too small for other people to notice.

- 7. Have you sometimes repeated sounds over and over, like clicking, clucking, humming, grunting or smacking? Don't count humming music to yourself that you do on purpose or for fun.

Competing Interests: No competing interests were disclosed.

Author Response ( F1000Research Advisory Board Member ) 31 Jan 2017

Kevin J Black, Washington University School of Medicine, St. Louis, USA

Additional video resources on TS include:

- Jankovic J. A Video Guide to the Diagnosis of Tourette Syndrome. Tourette Syndrome Association, www.tsa-usa.org, 2008.

- Video atlas supplement to: Singer HS, Mink JW, Gilbert DL, Jankovic J. Movement Disorders in Childhood, 2nd edition, Butterworth-Heinemann (Elsevier), Philadelphia, PA, 2016:1-587.

Competing Interests: No competing interests were disclosed.

\section{Version 1}

\section{Reader Comment 10 Aug 2016}

Irene Malaty, University of FIroida, USA

The authors have attempted to address a longstanding problem in TS epidemiologic research, which is the challenge in capturing tic prevalence when recognition and trends in seeking healthcare are variable. Previous "real world" observational ascertainment techniques have often utilized limited face time in single environments. The authors have produced a video educational tool to help involve community members who have consistent time observing (or living with) potential tic behaviors across time and environments. This could increase the reach of tic screening and possibly increase sensitivity for detecting tic behaviors.

The video has as its strengths simple language and short clips. I particularly like the inclusion of short clips that reinforce particular tics being discussed when cataloguing body regions and tic types in the second half of the video. No tool is perfect, and a novice evaluator may not obtain 
from this video the ability to distinguish actual causes of observed behaviors. For instance, one might misclassify idiopathic blepharospasm as a tic. A person with chorea would also be scored for having movement of the arms or legs, which would not be tics. Similarly, psychogenic movements could be classified as tics. On the other hand, even experts may need further questioning to distinguish such diagnoses from tics. In summary, specificity of using lay assessments may be questionable. This may or may not be acceptable in a screening tool.

It would be interesting to learn how this tool may be implemented in practical terms. Process for consenting participants will need to be considered. Would schools be target sites for dissemination? How would it be distributed in a way that would sample a wider audience than prior tools have?

This may indeed be a great educational tool for screening larger populations, and even for helping clinicians collect information from patients. Validating this tool against currently accepted means of diagnosing Tourette (involving expert assessments) in a subset of participants will help confirm its utility.

I enjoyed watching the video and thank the authors for sharing this interesting project.

Competing Interests: I am on the medical advisory board of Tourette Association of America (TAA) and direct a TAA center of excellence. I have participated in Tourette research funded by Auspex and Neurocrine. None of these present conflicts with my comments.

The benefits of publishing with F1000Research:

- Your article is published within days, with no editorial bias

- You can publish traditional articles, null/negative results, case reports, data notes and more

- The peer review process is transparent and collaborative

- Your article is indexed in PubMed after passing peer review

- Dedicated customer support at every stage

For pre-submission enquiries, contact research@f1000.com 